\title{
Permeability of Ultra-Fine Reactive Fly Ash applied to Cement-Based Composites
}

\author{
Wei-Ting Lin ${ }^{1}$, An Cheng ${ }^{1}$, Wei-Chung Yeih ${ }^{2}$, Kinga Korniejenko ${ }^{3}$, Marek Hebda ${ }^{3}$ and \\ Michal $\mathbf{L a c h}^{3}$ \\ ${ }^{1}$ Department of Civil Engineering, National Ilan University, No.1, Sec. 1, Shennong Rd., I-Lan 260, \\ Taiwan,wtlin@niu.edu.tw \\ ${ }^{2}$ Department of Harbor and River Engineering, National Taiwan Ocean University, No. 2, Beining \\ Rd., Keelung City 20224, Taiwan, wcyeih@mail.ntou.edu.tw \\ ${ }^{3}$ Institute of Materials Engineering, Faculty of Materials Engineering and Physics, Cracow University \\ of Technology, Warszawska 24, 31-155 Kraków, Poland, kkorniej@gmail.com
}

\begin{abstract}
This study explores the permeability of the partial replacement of cement using ultra-fine reactive fly ash (URFA) and silica fume. URFA is an industrial by-product from thermal power plants and it has a smaller spherical particle size $(0.1 \mu \mathrm{m}$ to $10 \mu \mathrm{m})$ than the general fly ash. The fixed water-to-binder ratio was 0.45 and the replacement of cement was used as $5 \%$ and $10 \%$. The combinations of URFA and silica fume in composites were used as 5\% URFA plus 5\% silica fume and $8 \%$ URFA plus $2 \%$ silica fume. The results show that the inclusion of URFA was enhanced to increase the workability, and help to produce pozzolanic reaction and C-S-H colloids. The colloids were filling the pore structures to increase the compactness of specimen, which is consistency with the increased the compressive strength and reduction of the dry shrinkage. It also was reduced the chloride ion penetration and non-steady state migration coefficient, which is helpful for improving the mechanical properties and permeability. The composites with 10\% URFA had a better performance. For blending specimen, it was also a tendency to improve mechanical properties and permeability; and the combination of 5\% URFA and 5\% silica fume in composites enhanced better performances.
\end{abstract}

Keywords: Ultra-Fine Reactive Fly Ash, Chloride Diffusion, Durability, Pore Structures.

\section{Introduction}

Fly ash is a popular pozzolanic material with high $\mathrm{SiO}_{2}$ and $\mathrm{Al}_{2} \mathrm{O}_{3}$ content. When cemented with water, the cementing performance is relatively low (Yang et al., 2018), but it will be activated by hydroxide ions $\left(\mathrm{OH}^{-}\right)$. Fly ash is usually added to cement as a pozzolana because it can be cured in wet conditions or underwater and further protect hardened materials from chemical attack. In most cases, fly ash is obtained from thermal power stations and is recycled as a pollution control measure, usually blended with ordinary cement to improve cement performance (Li et al., 2014).

Fly ash is sufficiently reactive when it reacts with water and $\mathrm{CaO}$ in the cement (Telesca et al., 2017). At room temperature, $\mathrm{C}-\mathrm{S}-\mathrm{H}$ gels are formed in the internal structure of the mixture, thereby forming hydraulic cementitious materials (Temuujin et al., 2009; Duan et al., 2017). Fly ash is also used to improve the performance of concrete in the fresh and hardened state, for improving workability, attaining high compressive strength at the early age, achieving long-term compressive strength, low drying-shrinkage and creep coupled with 
excellent durability properties (Zuquan et al., 2007; Xu et al., 2017; Ahmad et al., 2019; Tan et al., 2019).

Several prominent researchers have devoted time to exploring the characteristics and application of fly ash in cementitious materials over the years and the general categories in which fly ash can be grouped regarding its effect on concrete includes morphological, active and micro-aggregate effects (Aiqin et al., 2003; Aiqin et al., 2004; Li et al., 2013; Gardner et al., 2015; Xu et al., 2017). In concrete, fly ash has several functions as the concrete ages. In the early age stage, fly ash can act have a physical effect in that it fills up spaces in the microstructure of the concrete and it is also involved in the formation of ettringite. In the long term, they mainly participate in the hydration reaction in the form of silicon-aluminum binders (Shi et al., 2006). At a later age, fly ash has two effects: it enhances the cohesion between molecules within the particle structure, and also absorbs the $\mathrm{Ca}(\mathrm{OH})_{2}$, reducing its effect (Kolias et al., 2005; Brostow et al., 2016). However, Most of the molecules of the fly ash remain un-reacted even after a long period of curing, so fly ash may also be considered as a composite material with the ash particles serving as reactive micro-aggregates (Nadesan et $a l ., 2018)$. Structurally, fly ash is composed of lots of fine spherical micro-spheres, which are large glassy particles existing in a crystalline internal structure of fly ash. Due to density difference, the internal molecules of fly ash which are also called micro-beads or microspheres, are classified as sinking beads and floating beads (Li et al., 2014). These microspheres are obtained from pulverized fuel ash (also called pulverized fly ash in some countries).

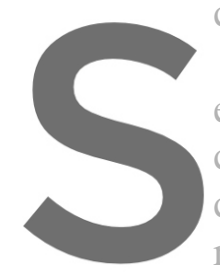

In the past decade extracted by processing construction industry composition with the cor research has shown that URFA exhibited

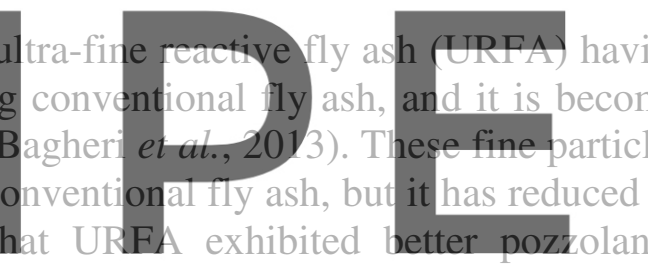
performance in concrete than normal fly ash (Elsayed et al., 2011; Duan et al., 2018; Han et ing very fin particles have been
ning increasingly popular in the
es often have a sinnilar chendical
surface area per particle. Recent
ic activity and more desirable

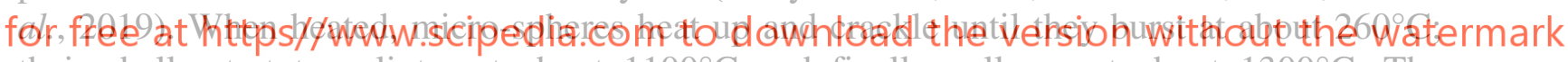
their shells start to splinter at about $1100^{\circ} \mathrm{C}$ and finally collapse at about $1300^{\circ} \mathrm{C}$. The superfine particles obtained can then be used to partially replace Portland cement in cementing material systems and their particulate structures. This study aims to determine its suitability as a pozzolanic additive to improve the performance of cement-based materials.

\section{Experiments}

\subsection{Materials}

Type I Portland cement was used in this study and it had a specific gravity of 3.15 and fineness of $3310 \mathrm{~cm}^{2} / \mathrm{g}$. The fine aggregates are natural river sand, it has an SSD specific gravity of 2.69 , an absorption of $1.45 \%$ and a fineness modulus of 2.73 . The specific gravity and specific surface area of silica fume is 2.20 and $22500 \mathrm{~m}^{2} / \mathrm{kg}$, respectively. Silica fume having an average content of $94.1 \%$ silicon dioxide was used in powder form. URFA was provided by TRIAXIS Corporation from a power plant in Inner Mongolia. The specific gravity and specific surface area of URFA is 2.20 and $3380 \mathrm{~m}^{2} / \mathrm{kg}$, respectively. URFA has an average content of $49.11 \%$ silicon dioxide, $28.07 \%$ aluminum oxide and $8.84 \%$ calcium oxide. 
The SEM photo of URFA particles is shown in Fig. 1 and the average particle size was between $0.1 \mu \mathrm{m}$ to $10 \mu \mathrm{m}$.

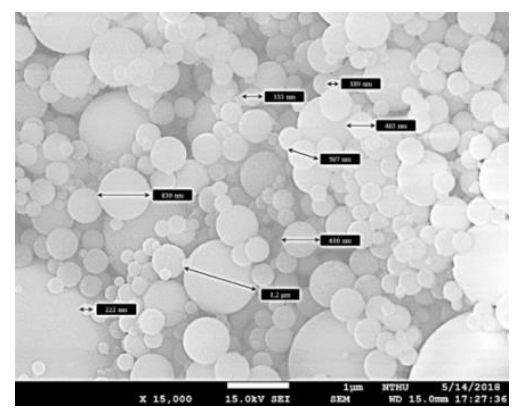

Figure 1. SEM photo of URFA.

\subsection{Mix Design and Test Methods}

According to the ASTM C109 specification, the water/cementitious ratio (w/c) of the mortar specimens was kept constant at 0.45 , while the mass ratio of the cementitious /fine aggregates was 1: 2.75. Table 1 lists the mix designs for all mixes. The specimens were numbered using the letters and numbers to indicate the kind of replaced materials and dosage of the replaced materials. OPC, F, S denotes ordinary Portland mortar, URFA and silica fume; 5 and 10 refers

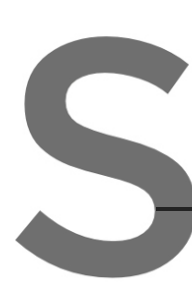

to specimens containing

Mix no. Water
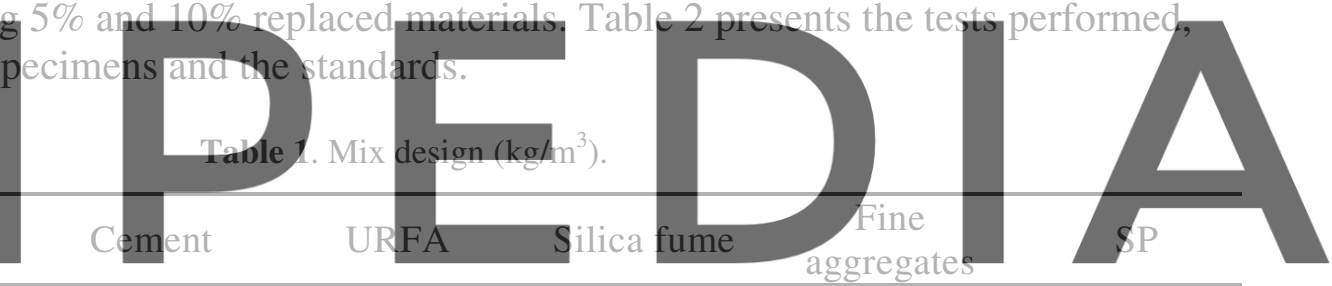

OPC 242.6

547.9

0

1506.7

4.0

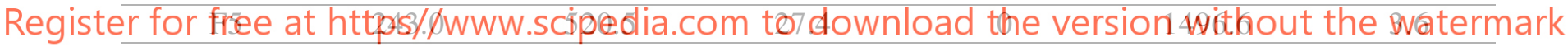

\begin{tabular}{ccccccc}
\hline F10 & 244.0 & 493.1 & 54.8 & 0 & 1486.5 & 2.5 \\
\hline S5 & 241.9 & 520.5 & 0 & 27.4 & 1496.6 & 4.7 \\
\hline S10 & 240.9 & 493.1 & 0 & 54.8 & 1486.5 & 5.7 \\
\hline F5S5 & 242.1 & 493.1 & 27.4 & 27.4 & 1486.5 & 4.5 \\
\hline F8S2 & 243.4 & 493.1 & 43.8 & 11.0 & 1486.5 & 3.2 \\
\hline
\end{tabular}

Table 2. Test methods.

\begin{tabular}{cccc}
\hline \multicolumn{2}{c}{ Test Target } & $\begin{array}{c}\text { Specimen } \\
\text { Dimensions }(\mathrm{mm})\end{array}$ & Referenced Standard \\
\hline Fresh properties & Flow test & - & ASTM C230 \\
\hline $\begin{array}{c}\text { Mechanical } \\
\text { properties }\end{array}$ & $\begin{array}{c}\text { Compressive } \\
\text { strength test }\end{array}$ & $50 \times 50 \times 50$ & ASTM C109 \\
\hline Durability & $\begin{array}{c}\text { Drying shrinkage } \\
\text { test }\end{array}$ & $285 \times 25 \times 25$ & ASTM C596 \\
\cline { 2 - 4 } & $\begin{array}{c}\text { Rapid chloride } \\
\text { penetration test }\end{array}$ & $\phi 100 \times 50$ & ASTM C1202 \\
\hline
\end{tabular}


Wei-Ting Lin, An Cheng, Wei-Chung Yeih, Kinga Korniejenko, Marek Hebda and Michał Łach

\begin{tabular}{cccc}
\hline Micro-structure & $\begin{array}{c}\text { Mercury intrusion } \\
\text { porosimetry test }\end{array}$ & $10 \times 10 \times 1$ & ASTM D4404 \\
\cline { 2 - 4 } & SEM observation & $10 \times 10 \times 1$ & ASTM C1723 \\
\hline
\end{tabular}

\section{Results and Discussion}

\subsection{Flowability}

The results of flow test for all mixes are summarized in Table 3. The fluidity of the mortar specimens was controlled at $110 \pm 3 \%$ using appropriate amount of superplasticizer. The results indicated that the dosages of superplasticizer had a decrease trend with the increase in the replacement of URFA due to the due to its perfect spherical shape and micro-sized particles. However, the flowability had a decrease trend with the increase in the inclusion of silica fume due to its larger surface area. The desired flow and rheological properties will determine the optimal design mix that 10\% URFA in mortar specimens should be used. The combination of silica fume and URFA in mortar specimens still had great flowability and F8S2 specimens had lowest dosages of superplasticizer at the desired flow.

Table 3. Example of the construction of a table.
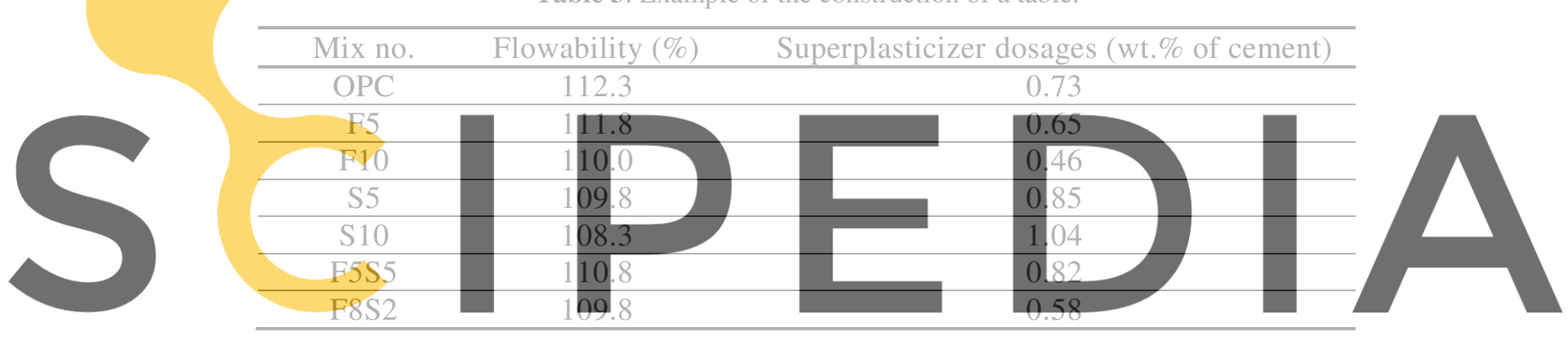

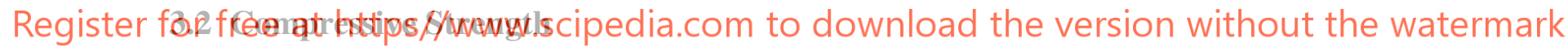

The results of compressive strength test for all mixes are illustrated in Figure 2. As expected, the specimens containing 10\% silica fume had highest compressive strength for ail ages. The strength development trend of F10 specimens was closed to that of the S5 specimens. Compared with silica fume, URFA has a much smaller specific surface area, so it can increase bulk density without excessively increasing the total solid surface area. It is able to fill the voids in cement to increase the packing density of the cementitious materials. The compressive strengths of the F5S5 specimens were higher than that of the S5 specimens and F8S2 specimens; and the compressive strengths were lower that of the S10 specimens. URFA is considered to be a good filler for increasing parking density without excessively increasing surface area. It has a particle size of micrometer-scale and is spherical in shape. It is finer than cement and ordinary fly ash. Inclusion of URFA showed improved properties in compressive strength due to the active pozzolan reaction and filling effect. 


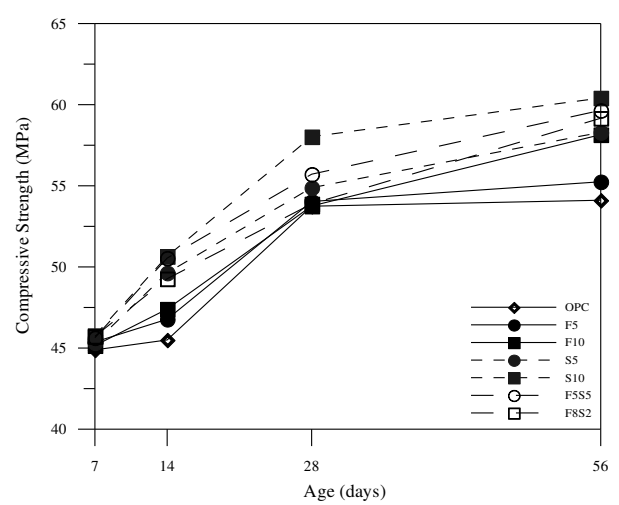

Figure 2. Compressive strength development curves.

\subsection{Drying Shrinkage}

The results of drying shrinkage test for all mixes are summarized in Figure 3. It indicated that drying shrinkage of the specimens containing URFA was lower than that of the specimens containing silica fume and control specimens. URFA can efficiently inhibit the dry shrinkage of mortar specimens due to the smaller specific surface area. URFA has a late hydration reaction and the dispersion effect on the cement particles can reduce the total hydration heat of the paste, and improve the drying shrinking performance.
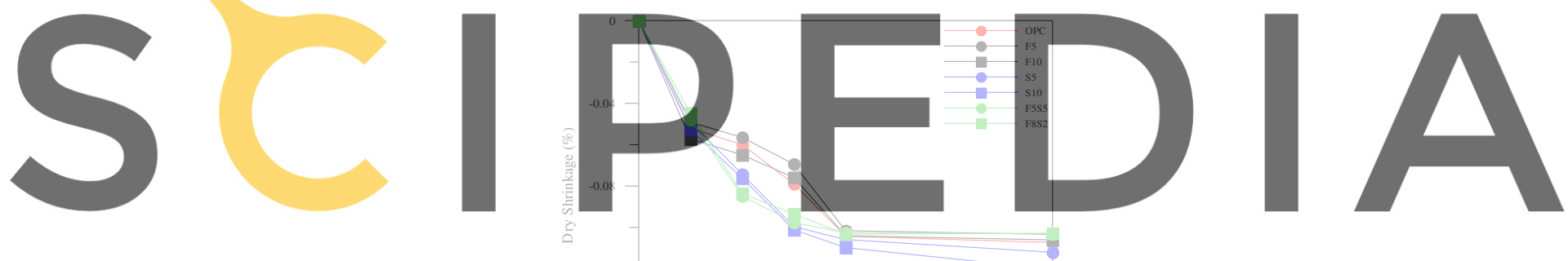

Register for free at https//www.scipedia.com to download the version without the watermark

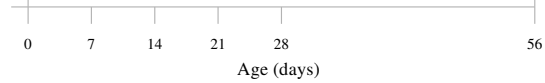

Figure 3. Dry shrinkage curves.

\subsection{Chloride Penetration}

The results of rapid chloride penetration test for all mixes are illustrated in Figure 4. The results indicated that the total charge passed of control specimens was higher than 10000 coulombs and the operated temperature of control specimens was higher than $90{ }^{\circ} \mathrm{C}$. The test of control specimens has been stop because the temperature of the solutions should not be allowed to exceed $90{ }^{\circ} \mathrm{C}$ in order to avoid damage to the cell and to avoid boiling off the solutions. As expected, the specimens containing 10\% silica fume had lowest total charge passed due to the finer particles. The trend of F5S5 specimens is closed to that of S5 specimens, which is due to the pore structure modification. Finer silica fume and URFA particles mixed into the mortar specimens improved the compactness through pozzolanic reactivity and pore filling effect. It may be as mainly hydrated reaction that $\mathrm{Ca}(\mathrm{OH})_{2}$ reacted 
with $\mathrm{SiO}_{2}$ or $\mathrm{Al}_{2} \mathrm{O}_{3}$ to form C-S-H or C-A-S-H colloids.

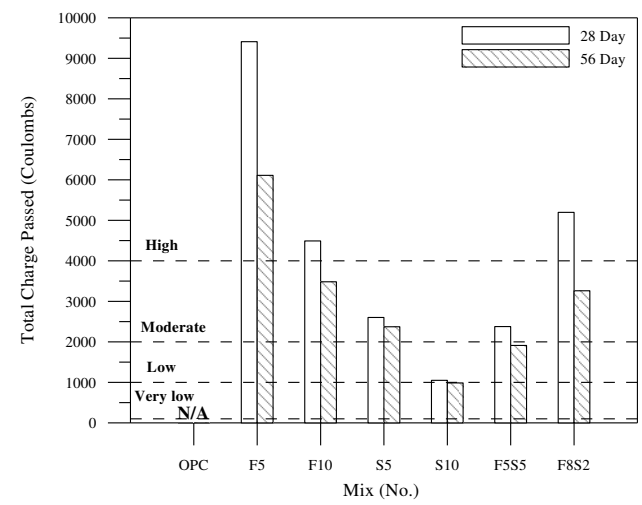

Figure 4. Total charge passed histograms.

\subsection{Pore Structures}

The MIP test results of the specimens containing URFA and control specimens are shown in Fig. 5. It indicated that the cumulative intrusion of specimens containing URFA significantly decreased that the control specimens. It was confirmed that the finer particles of URFA was useful to the pore structure modification, which is in agreement with the results of chloride penetration tests and compressive strength tests.
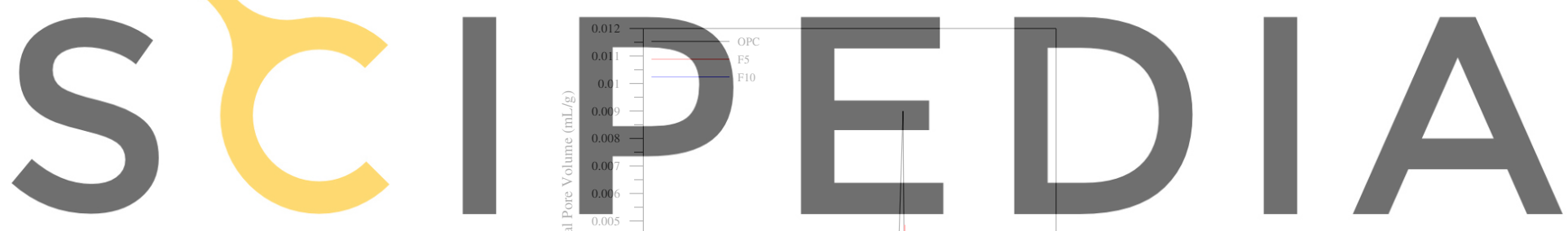

Register for free at https//www.seip.e clia.com to downlload the version without the watermark

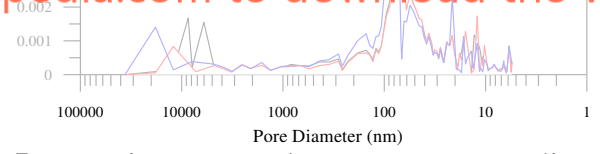

Figure 5. Intrusion pore volume versus pore diameter.

\subsection{SEM Observations}

It took SEM images of the various specimens at 28 days at 5000x magnification as illustrated in Figure 6. The results showed small porosity and smooth surface in the URFA or silica fume specimens than in the control specimens. Many pores in the URFA or silica fume specimens were filled with ettringite and C-S-H gel. C-S-H gel is the product of the hydrated reaction between water and tricalcium silicate or dicalcium silicate. Finer particles are needed to fill these pores. As shown, most of the pores have been filled with ettringite and C-S-H gel, which presents a dense appearance and reduces the chance of penetration of harmful substances. However, an increased amount of URFA may cause a partial reaction in the hydration process. Non-react particles of URFA can be seeing in the surface of the microstructures. URFA is excellent cementitious filler for improving the flowability and strength of 
cement pastes as shown in SEM photos and it needs more curing age to keep a continued hydration reaction.

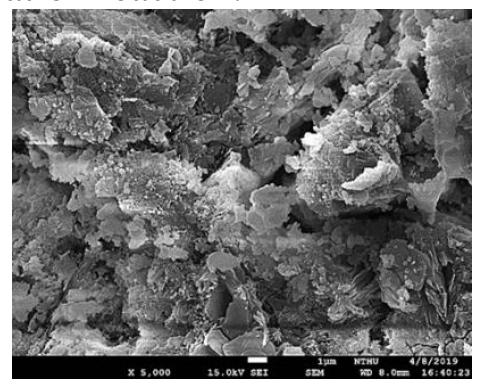

(a) control specimens

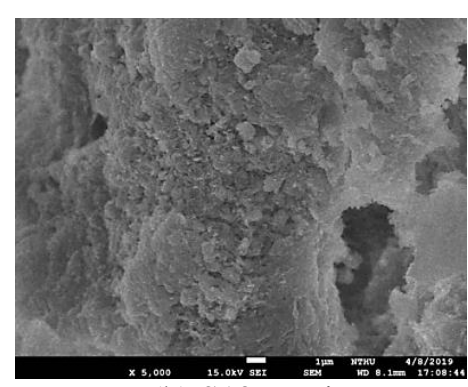

(b) S10 specimens

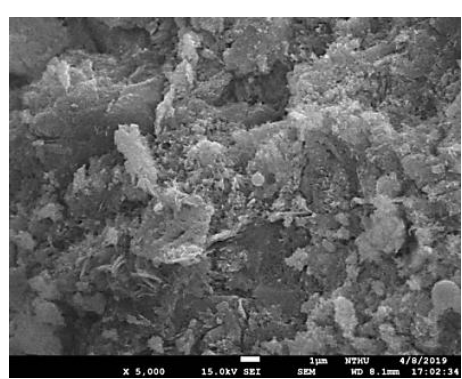

(c) F10 specimens
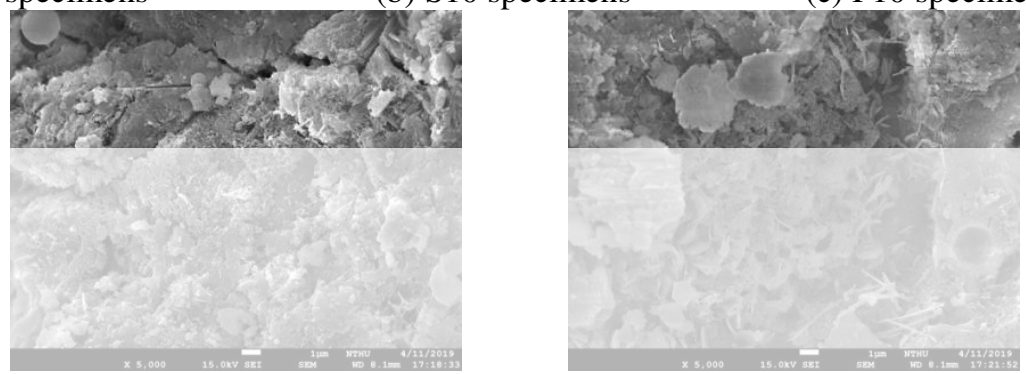

(d) F5S5 specimens

Figure 6. SEM photos for each mixtures (x5000).

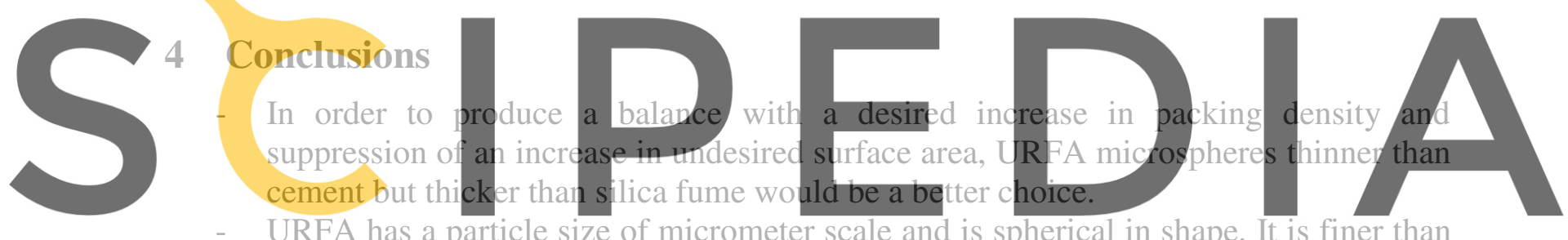

URFA has a particle size of micrometer scale and is spherical in shape. It is finer than

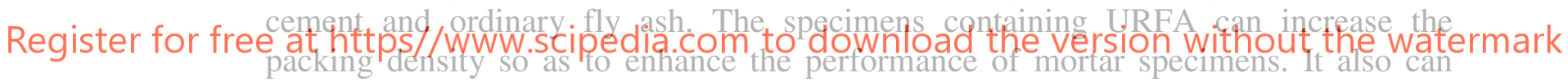

significantly decrease the dry shrinkage.

- SEM observations and MIP analysis confirmed that the finer particles of URFA were useful to the pore structure modification, which is in agreement with the results of chloride penetration tests and compressive strength tests.

- Environmental friendly and helps to reduce the carbon footprint produced in cement production, since it can be used to replace cement in cement mixtures, and from a life cycle assessment perspective. It is feasible to consider URFA as a relatively $\mathrm{CO}_{2}$ free resource.

\section{Acknowledgements}

This support of the Ministry of Science and Technology (MOST) under the grant MOST 108-2221-E-197-006 in Taiwan is gratefully acknowledged. This work has been financed by the by Polish National Agency for Academic Exchange w under the International Academic Partnership Programme within the framework of the grant: E-mobility and sustainable materials and technologies EMMAT.

\section{ORCID}

Wei-Ting Lin: https://orcid.org/0000-0003-4792-4457 
Kinga Korniejenko: https://orcid.org/0000-0002-8265-3982

Marek Hebda: https://orcid.org/0000-0002-8583-9459

Michał Łach: https://orcid.org/0000-0001-5713-9415

\section{References}

Aiqin, W. Chengzhi, Z. and Wei, S. (2003). Fly ash effects: I. The morphological effect of fly ash. Cement and Concrete Research, 33(12), 2023-2029.

Aiqin, W. Chengzhi, Z. and Wei, S. (2004). Fly ash effects: II. The active effect of fly ash. Cement and Concrete Research, 34(11), 2057-2060.

Ahmad, M.R. Chen, B. and Yu, J. (2019). A comprehensive study of basalt fiber reinforced magnesium phosphate cement incorporating ultrafine fly ash. Composites Part B: Engineering, 168, 204-217.

Bagheri, A. Zanganeh, H. Alizadeh, H. Shakerinia, M. and Marian, M.A.S. (2013). Comparing the performance of fine fly ash and silica fume in enhancing the properties of concretes containing fly ash. Construction and Building Materials, 47, 1402-1408.

Brostow, W. Chetuya, N. Hnatchuk, N. and Uygunoglu, T. (2016). Reinforcing concrete: comparison of filler effects. Journal of Cleaner Production, 112, 2243-2248.

Duan, P. Yan, C. and Zhou, W. (2017). Compressive strength and microstructure of fly ash based geopolymer blended with silica fume under thermal cycle. Cement and Concrete Composites, 78, 108-119.

Duan, S. Liao, H. Ma, Z. Cheng, F. and Yang, H. (2018). The relevance of ultrafine fly ash properties and mechanical properties in its fly ash-cement gelation blocks via static pressure forming. Construction and Building Materials, 186, 1064-1071.

Elsayed AA. (2011). Influence of silica fume, fly ash, super pozz and high slag cement on water permeability and strength of concrete. Jordan Journal of Civil Engineering, 5(2), 245-257.

Han, X. Yang, J. Feng, J. Zhou, C. and Wang, X. (2019). Research on hydration mechanism of ultrafine fly ash and cement composite $\mathrm{C}$

Gardner, L.J. Bernal, S.A. magnesium potassium prestion Cement and Concrete

Kolias, S. Kasselouri-Rig fly ash and cement. C

Li, H. Xu, D. Feng, S.
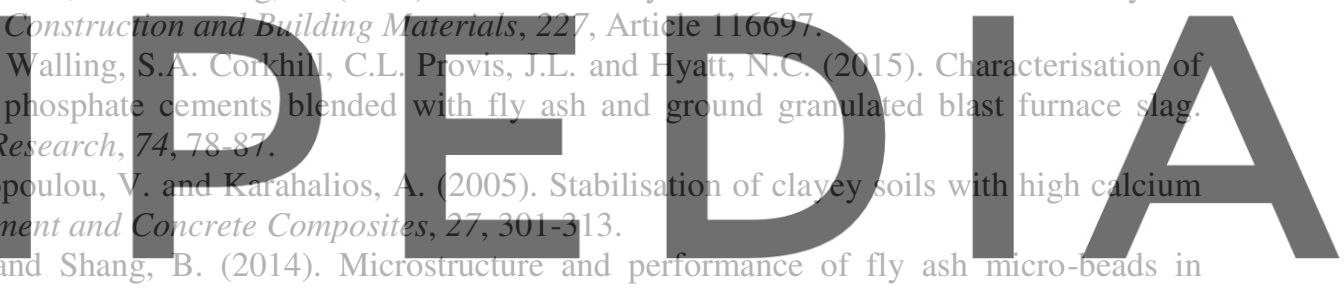
cementitious material system. Construction and Building Materials, 52, 422-427.

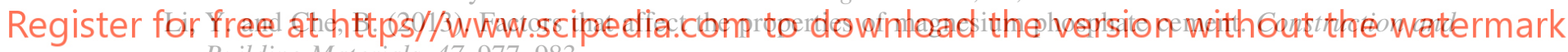
Building Materials, 47, 977-983.

Nadesan, M.S. and Dinakar, P. (2018). Micro-structural behavior of interfacial transition zone of the porous sintered fly ash aggregate. Journal of Building Engineering, 16, 31-38.

Shi, C. Krivenko, P.V. and Roy, D.M. (2006). Alkali-activated Cements and Concretes. Taylor \& Francis, London, New York.

Tan, H. Nie, K. He, X. Deng, X. Zhang, X. Su, Y. and Yang, J. Compressive strength and hydration of highvolume wet-grinded coal fly ash cementitious materials. Construction and Building Materials, 206, 248-260.

Telesca, A. Marroccoli, M. Ibris, N. Lupiáñez, C. Díez, L.I. Romeo, L.M. and Montagnaro, F. (2017). Use of oxyfuel combustion ash for the production of blended cements: a synergetic solution toward reduction of $\mathrm{CO}_{2}$ emissions. Fuel Processing Technology, 156, 211-220

Temuujin, J. van Riessen, A. and Williams, R. (2009). Influence of calcium compounds on the mechanical properties of fly ash geopolymer pastes. Journal of Hazardous Materials, 167(1-3), 82-88.

$\mathrm{Xu}, \mathrm{B}$. Ma, H. Shao, H. Li, Z. and Lothenbach, B. (2017). Influence of fly ash on compressive strength and micro-characteristics of magnesium potassium phosphate cement mortars. Cement and Concrete Research, 99, 86-94.

Yang, J. Su, Y. He, X. Tan, H. Jiang, Y. Zeng, L. and Strnadel, B. (2018). Pore structure evaluation of cementing composites blended with coal by-products: calcined coal gangue and coal fly ash. Fuel Processing Technology, 181(1), 75-90

Zuquan, J. Wei, S. Yunsheng, Z. Jinyang, J. and Jianzhong, L. (2007). Interaction between sulfate and chloride solution attack of concretes with and without fly ash. Cement and Concrete Research, 37(8), 1223-1232. 